\title{
"It's like me leaving a manual of me behind": Parents talk about succession planning of long-term care and support for their disabled adult children with high and complex needs
}

\author{
Hemant Thakkar
}

\begin{abstract}
INTRODUCTION: A question that concerns most parents of disabled adults with high and complex needs (HCN) is: "What will happen to my child when I am no longer alive?" One of the factors that could assist these parents in securing a better future for their children beyond their own lifetime is timely succession planning.

METHOD: Semi-structured interviews were conducted with 14 Aotearoa New Zealand parents and 18 Indian parents with a view to understanding their wishes and worries concerning the long-term care and well-being of their adult children with HCN. This article focuses on the parents' views on their own role in succession planning.
\end{abstract}

FINDINGS: Based on parents' responses, six key components of succession planning were identified: preparing the child; preparing the informal network; sorting out the living arrangements; securing their financial future; creating a life plan and a training manual; and preparing the community.

IMPLICATIONS: The study revealed that not all parents have the necessary skills, resources or even desires to engage in succession planning and hence it becomes crucial that professionals working in the social services sector provide appropriate support to these parents.

KEYWORDS: high and complex needs; succession planning; disabled adults; parents of disabled children

\section{INTRODUCTION}

What will happen to my child when I am no longer alive? Whilst this question often troubles many parents of disabled children, for a majority of the ageing parents of adult children with high and complex needs $(\mathrm{HCN})$, this is perhaps the most worrisome question as, even within the disability population, people with $\mathrm{HCN}$ are considered to be the most vulnerable group. Their increased vulnerability compared to other disability groups could be attributed to the nature of the support they require (including intimate personal care) associated with deficits in cognitive and communication abilities to speak up and fight for their own rights. Milner and Mirfin-Veitch (2012) argued
AOTEAROA

NEW ZEALAND SOCIAL WORK 30(2), 3-15.

CORRESPONDENCE TO: Hemant Thakkar hemantthakkar@xtra.co.nz 
that the total reliance of people with $\mathrm{HCN}$ on others for most aspects of their everyday lives also makes them more susceptible to various kinds of abuse and neglect. Therefore, in most cases, the parents of children with HCN end up assuming multiple roles in their children's lives including being their primary carer, their friend/companion, their interpreter, their advocate, their welfare guardian, and their financier or finance manager. However, playing such multiple roles often has a negative impact on the mental and physical health of the parents (Morgan, 2009). In addition to spending a significant amount of time attending to the needs of their children with HCN, these parents might also have other children requiring their attention. This leaves them with very little time and energy to do anything for themselves and their life becomes captive around their children (Bray, Moss, Forrester, \& McConnochie, 2005; Vorhaus, 2014). However, given the vulnerability of their children, despite the personal toll caring takes on them, facing the prospect of leaving their children under someone else's care, becomes a matter of great concern for the parents of children with $\mathrm{HCN}$.

The level of concern felt by the individual parents would, though, depend upon their perception of how well their children will be supported in the future when they are no longer there to care or advocate for them. For most parents, irrespective of where they live, the support network that they would rely upon to look after their children when they are no longer alive would comprise of both formal (publicly funded) support and informal support (provided voluntarily by family, friends and others). Whilst in some cases, the support provided by family and friends could also be publicly funded, for the purposes of this study, informal support is defined as the support provided without any monetary compensation. The availability of, and access to, both formal and informal support, however, differs for parents living in different parts of the world. For example, in India, state funding in the disability sector is very limited and, as a result, disabled people and their families are generally more reliant on their friends and extended family members to meet their care and support needs (Pinto \& Sahur, 2001; Rehabilitation Council of India, 2014). On the other hand, the New Zealand government has made significant financial investment in the disability sector in recent years and as a result there is reasonably well-established disability support structure in Aotearoa New Zealand (Ministry of Health, 2016). Thus, India and Aotearoa New Zealand represent those countries where disabled people and their families are generally more reliant upon informal and formal support, respectively.

Further, the literature suggests that, despite the efforts of the policy makers to provide better services that align with the rights of the disabled people under the United Nations Convention on the Rights of Persons with Disabilities (UNCRPD), the prevalent support models such as "direct payments" or "individualised funding" have been unsuccessful in meeting the needs of the end service users (Larkin \& Mitchell, 2016). It has been argued that one of the key reasons for even the contemporary models of delivering disability support failing to adequately meet the support needs of all service users is that there is little policy consideration of family voice and choice (Larkin \& Mitchell, 2016). To find any workable solution towards bridging the gap between ideal and affordable support, it is important in the first instance to get a real understanding of what kind of supports disabled people and their families value as being useful. Policy makers can gain such real understandings by consulting with the people whose lives it might impact before making crucial policy decisions. However, the literature suggests that the support needs of adults requiring ongoing care and support and their ageing parents have been poorly studied (James, 2013; Shaw, Cartwright, \& Craig, 2011; Wong \& Wong, 2003). Thus, there is a lack of focused discussion in the international disability discourse on the specific support needs of the people with $\mathrm{HCN}$ and their families. A doctoral study (Thakkar, 2017), the relevant findings of 
which are discussed in this article, was conducted with a view to making its own contribution towards this identified need for further research and also towards bringing the voice and concerns of the parents of adults with HCN to the forefront.

One of the crucial components of the study was to explore the parents' views on the changes required in their then existing support system that could help in fulfilling their wishes and reducing their worries concerning their children's future. The changes proposed by the parents primarily included either the actions they needed to take themselves during their lifetime and/or the actions they wanted the government to take. This article focuses on what the parents shared about the actions they needed to take themselves as part of succession planning.

\section{Literature review}

Parenting a disabled child is reported, time and again in numerous studies, to be far more complex and stressful than raising a non-disabled child (Bennett, 2002; Harrison, Henderson, \& Leonard, 2007; Read, 2000; Wills, 1994). The issues faced by parents in raising a disabled child as reported in the literature include:

- difficulties in managing work-life balance;

- feelings of losing their own identity other than being a parent of a disabled child;

- $\quad$ stress in relationship with their partners/other family members;

- loss of friends and feelings of isolation;

- poor health outcomes; and

- worries about, if something happened to them, what would happen to their child.

Further, disabled adults, in general, require more support services involving more government agencies than those required by younger disabled children. However, even within the population of disabled adults, the needs of adults with $\mathrm{HCN}$ are even higher as they often have other associated health-related conditions and behavioural issues requiring constant care and supervision, including attending to their intimate personal care (Hewitt-Taylor, 2008). Consequently, as the parents get older and their adult children become physically bigger and stronger, caring for them becomes increasingly difficult. Thus, for the parents of children with HCN, the impact on their lives of raising a disabled child (as reported above) continues beyond their children's childhood and right up to their adulthood. Parents of children with HCN often do not get to do things for themselves that others can, such as taking vacations and pursuing hobbies that require time away from home; and their lives can become captive to their disabled children's needs.

Maintaining resilience in the face of such multiple complexities is not an easy task. It is only natural then for the parents of adults with HCN to be concerned about what would happen to their children if something happened to the parents. Unfortunately, some parents get so concerned about their children's future beyond their own lifetime that they "often express the hope to survive the child by at least 5 minutes, so it won't be a problem. Some parents have actually taken tragic steps to assure they survive their child" (Morgan, 2009, p. 20). However, most parents of adults with HCN manage to do the job of caring and advocating for their children tirelessly and with as much grace as is humanly possible.

Research suggests that timely succession planning on the part of the parents can help alleviate some of the worries that they have concerning their disabled children's long-term future (Hatton, Akram, Shah, Robertson, \& Emerson, 2004; Redmond \& Richardson, 2003; Taggart, TruesdaleKennedy, Ryan, \& McConkey, 2012). Unfortunately, however, the same studies have also reported a lack of planning on the parents' part or even a reluctance to engage in planning. For example, during their review of the relevant literature, Taggart et al. found that: 
Carers may not make plans as a result of denial about the inevitability of their own mortality and the realisation that they will not be able to provide care indefinitely. Moreover, they have difficulties in letting go of their loved ones as it may mean increased loneliness for them and an end to their role in life... They find the subject too painful to broach and do not make firm plans until it becomes unavoidable. (Taggart et al., 2012, p. 219)

Thus, many parents avoid future planning as it is a very sensitive topic that might force them to face a lot of their own insecurities, anxieties or inhibitions. Whilst a reluctance towards planning on some parents' part might be understandable, the literature, nevertheless, suggests that it is certainly neither advisable nor desirable to delay the planning until it reaches a point of crisis. The potential dangers of a lack of timely planning include the adult child not acquiring the necessary functional skills to be independent (Shaw et al., 2011); the child being forced to move to an institution and/or live a diminished quality of life (Broadbent, 2003); emotional trauma and unexpected dilemmas for the family and a sudden demand placed on the formal support system (Taggart et al., 2012). Timeliness is crucial - if the parents do not make their and their children's wishes explicit to others in a timely manner, the future decisions taken by others might not be in the best interests of their child.

\section{Method}

The primary aims of this study were to: a) understand the wishes and the worries of the parents of adults with HCN concerning their children's future; b) understand the support mechanisms (both formal and informal) that they consider and value as being useful for their children's future; and c) make useful recommendations for design and delivery of disability services catering for the specific support needs of adults with $\mathrm{HCN}$ and their families.
With the above aims in mind, the following two key research questions were identified:

1. What are the wishes and the worries of the parents of adults with $\mathrm{HCN}$ concerning the long-term care and wellbeing of their children?

2. What type of supports (both formal and informal) do parents consider as being crucial for their children's future, especially when they are no longer there to care and advocate for them?

Given the sensitive nature of the topic, a qualitative methodological approach was considered appropriate for this study. Using purposive sampling, 14 parents from Auckland, Aotearoa New Zealand and 18 parents from Delhi, India were selected as the participants for this study. The primary purpose of choosing the participants from India and New Zealand was to provide a unique insight into what influence does living in countries with varied levels of formal and informal support have on the wishes and worries of the parents of children with HCN concerning their children's longterm future.

It was considered that, in addition to interviewing parents in the two geographical contexts, interviewing key informants would be valuable particularly for developing robust recommendations from a service delivery perspective. A total of 13 key informants were interviewed six in Auckland and seven in Delhi. The key informants were chosen from the researcher's professional network and represented a mix of disabled people themselves, academicians, government officers, service providers and the NGO sector. All the participants were provided with a Participant Information Sheet (PIS) and an Informed Consent (IC) form approved by the University of Auckland Human Participants Ethics Committee (UAHPEC). Other ethical issues that were considered to be of special significance for this study included social and cultural 
sensitivity and minimising harm. These were addressed appropriately by approaching interviews with great respect and sensitivity towards individual participant's cultural norms and emotional state of mind, respectively.

Personal interviews were conducted with all the participants using a semi-structured interview schedule. All the interviews were audio recorded and transcribed by the researcher. Finally, thematic analysis of the transcripts was conducted to generate meaning from the data. As part of this process, the transcripts were first auto-coded using $\mathrm{NVivo}^{\mathrm{TM}}$, a qualitative data analysis software, based on the broad questions used in the interview schedule. Each auto-coded question was then reviewed line by line to identify the emerging key themes based on the participants' responses. A combination of Axial coding, In-vivo coding, and Open coding was used to identify themes and sub-themes.

\section{Findings}

Note: To protect the identity of the participants, pseudonyms are used for the parents as well as their children throughout this section including in the parents' quotes where they refer to their children.

In addition to asking parents about their wishes and worries concerning their children's future, this study also explored parents' views on the changes required in their then-existing support system that could help in securing a better future for their children beyond their own lifetime. Many parents seemed to have given it serious thought and offered a lot of ideas and suggestions including on what succession planning they needed to do to secure their children's future. However, in line with what literature suggested, there were also some parents who had not thought much about the future as they intended to carry on their role for as long as they could. Donna (Auckland parent) felt that it was too early for them to start planning and suggested that, "to a certain extent there are things that can't be decided right now. I am not dead yet".
Kanchan (Delhi parent), on the other hand, had left things to destiny: "I allow the universe to unfold. I can't plan too much because I have realised that the best plans get made somewhere else."

The changes proposed by those parents who had started to think about the future, primarily included either the actions they needed to take themselves during their lifetime and/or the actions they wanted the government to take. Thakkar (2017) provides a detailed account of the suggestions Auckland and Delhi parents had for their respective governments to improve the lives of their children. This article reports the findings on the actions that the parents felt that they needed to take themselves as part of succession planning.

The key themes that emerged from the parents' suggestions around succession planning include: preparing the child; preparing the informal network; sorting out living arrangements; securing the child's financial future; creating a life plan and a training manual; and preparing the community.

It should be noted that, in addition to the parents' ideas on what they would do for their own children, the discussion here also includes their suggestions for other parents of adult children with HCN. In other words, the headings below could also be read as the key messages from the parent participants of this study to other parents in a similar situation to theirs.

\section{Prepare the child}

In most cases, people with HCN living at home are completely reliant on their parents for every aspect of their lives and hence they share a unique bond with each other. Given the closeness of their relationship, it would undoubtedly be extremely difficult for these children to live without their parents. Hence, it is not surprising that many parent participants of the study suggested that, first and foremost, what they would need to do 
is to prepare their children to live apart from them. Perhaps recognising the difficulties with mentally preparing their children with $\mathrm{HCN}$ to live without them, many parents felt that they could at least start preparing their children in such a way that they gradually become less dependent upon them for their various support needs. Several Auckland parents and many Delhi parents talked about training their children, where possible, to look after their own personal care needs and doing some household chores. They used terms such as their child being "self-dependent", "successful", "cognitively able", "alright", or even "fully cured" so that they can manage their own affairs. For example, Hema (Delhi parent) mentioned that "I would like to see that Jitesh becomes alright. If not, at least he should be self-reliant like in the areas of personal care and household work."

Some Auckland parents also talked about increasing the frequency of sending their children to a respite care home so that they gradually get used to the idea of not having the parents around all the time. Further, given their grave concerns around potential abuse, some parents also talked about somehow helping their children understand what abuse looks like and what to do if it ever happened. Finally, some Delhi parents talked about sending their children to a day centre where they could learn some useful social, artistic or vocational skills with a view to helping them to build relationships with others and also potentially earning some income and reducing their financial dependency on the parents.

\section{Prepare the informal network}

In addition to preparing the child, many parents also talked about preparing their informal network of family and friends in supporting their children after the parents' death. As previously discussed, parents play multiple roles in their children's lives and when parents are no longer there, it might be desirable or even necessary to share those roles between different people. In this regard, the parents identified a need for talking to their immediate and extended family, friends and relatives at an early stage about a) who would play what role in their child's future; and b) what support they would need in carrying out their respective roles. In terms of concrete actions, the parents' suggestions around preparing the informal network included identifying potential successor/s (to take primary charge of welfare of the person after the parents); appointing welfare guardian/s; creating a circle of support; and providing training to all concerned.

\section{Identify potential successor/s}

The parents were asked to talk about the top three changes that would help them die peacefully in relation to their worries concerning their children's future. In response, finding someone who could take over the direct care or the oversight of the formal care of their children was reported by many parents of both groups as one of the top three changes. Whilst a majority of the parents expected their other, non-disabled, children to be their successors, some Delhi parents suggested that their own younger siblings might take over that role. Several parents, however, held the view that ideally the parents should hand over the reins to someone of more-or-less similar age to their disabled child for long-term continuity of care.

While some parents had no idea about who that someone could be, the others talked about the potential role of other family members, a trust, a team of guardians, an individual professional, or an organisation taking over the caring role from them:

Yes, there should be someone to whom we can go and pass it on to, say this is what needs to happen when we are no longer here. (Donna, Auckland parent)

I would like to see Maxine maintain control over service provision and to meet the needs for her care under the guardianship of the shared guardianship team. (Louise, Auckland parent) 
First, the biggest things is that there should be someone - either through a government or an organisation's support - who will look after my child well. (Sunita, Delhi parent)

That his brother gives us assurance that you don't worry, I will take care of him. (Nita, Delhi parent)

One Delhi parent suggested that, if the parents expect their other, non-disabled, children to look after their disabled siblings after parents die, then they should have that conversation with their children as early as possible and in an open and honest manner.

In some houses parents don't talk face to face to their other children about the disabled child's future. We motivate our children to have a discussion [with us] and say that "if you don't discuss things with us how would we know that after we die how are you going to look after your brother". (Mrs Sharma, Delhi parent)

\section{Appoint welfare guardian/s}

None of the adults with HCN whose parents participated in this study had appointed (or had the cognitive ability to appoint) an Enduring Power of Attorney. Therefore, to support their children with decision making and/or financial management, many parents talked about either setting up a trust and/ or appointing someone as a legal welfare guardian for their children. Whilst some parents suggested that their successor would also become their child's welfare guardian, some talked about having multiple people involved in this role. Finding the right people for this role who have a good understanding of their children's needs and preferences could alleviate some of the parents' worries around decision making and potential financial exploitation.

\section{Create a circle of support}

Many parents also recognised a need for helping their children develop relationships and widening their children's social network as part of succession planning. The parents' suggestions included gradually increasing their children's social interaction with family, friends, relatives, and wider community; joining family support groups; or starting an informal club in their own house:

If I could get similar minded interested people who would come with their support workers and come and spend just one hour in his garage where people like him can come and spend a little time. You know just for plain recreation. It's supervised - we are there. Their parents can come, so a little club can start.

(Mrs D'souza, Auckland parent)

Creating a circle of support around the child could be helpful in a number of ways including assisting at times of emergency, in keeping the person safe, providing emotional support and avoiding issues associated with isolation and loneliness.

\section{Provide training}

Finally, as part of preparing the informal network to provide adequate support to their children, it would become vital for the parents to provide necessary training/ guidance to their successors, future guardians and all the other people who become part of their children's circle of support. The successors might need specific training in how to provide personal care and health care related needs, whereas welfare guardians or trustees might need briefing on their children's entitlements to various services and navigating the formal system. Furthermore, where children are unable to effectively communicate their needs and preferences to others, all people in such children's informal network would need training in non-verbal communication irrespective of the role they play. The parents need to train people in how to communicate with their children with a specific focus on the various signs, gestures and behaviours they use for communicating their needs and preferences. The parents are the best experts 
when it comes to supporting their children with HCN, and hence it becomes vital that, wherever possible, the parents provide this training themselves to all concerned whilst they are still around and able to do so.

\section{Sort out the living arrangements}

Sorting out the living arrangements for their children was also reported by a majority of the parents from both groups as one of the three most important changes that would help them die peacefully. In terms of concrete actions, depending upon their preference for future accommodation type, the parents talked about checking out the suitability of the available residential options for their children; buying or renting a house, transferring the house to their disabled child's name or in joint names with their other, non-disabled, children.

That we have fully settled him into a group home, where he is loved. (Holly, Auckland parent)

That I knew that there was a place where if we did die before him or couldn't look after him that I would feel comfortable about him going to. (Tania, Auckland parent)

Definitely I will be more in peace when I die if I see her happily living with my son's family. (Shobha, Delhi parent)

First, the biggest thing is as I said before, there should be an organisation where our kids can stay safely after us... They should start going there whilst we are still alive so we can be reassured that after us our child will live here for [their] lifetime. (Sangeeta, Delhi parent)

One Auckland parent suggested that, given the shortage of suitable residential options that cater to the specific support needs of their children, the parents need to be a bit more realistic in their search for out-of-home options and that they should also be willing to make some compromises.
One of the things that I keep telling myself and my family that initially we were looking for a perfect place for Maria - we let "perfect" get in the way of perfectly adequate. So, if we look for perfect - it won't happen; if we look for something where most of the boxes are ticked - we will find something. So we will have to make some compromises and some adjustments. (Mr Smith, Auckland parent)

\section{Secure the financial future}

Some Auckland parents and almost all the Delhi parents felt that, in addition to sorting out the living arrangements, they would also need to do something about securing the financial future of their children as otherwise their children might end up living at the mercy of others or of the welfare state. The concrete actions that the parents felt they needed to take in this direction during their lifetime included preparing a will, putting some funds in the child's name, getting assurance from other family members of their ongoing financial support for their children, setting up a small family-run business in the child's name, or working with the government to ensure that their children would continue to receive adequate lifelong financial support. As previously mentioned, a majority of the Auckland parents (including those who were financially affluent) expected the state to take full responsibility for their children's future financial needs.

Many Delhi parents felt that it might become easier to get informal support if the child was financially secure. They suggested that the parents should either leave enough funds in their child's name or ensure that there would be sufficient ongoing funding from the government to meet all their needs. People then might be more willing to provide support so long as they do not have to spend money.

If there is some help from the government then even other relatives will be interested in providing some help.... 
They will think that we don't need to do much, we just have to take him there and get things done and come back. Otherwise, if they think that I will have to put in money to get it done or run around to get things done then they take a back step. (Mr Sethi, Delhi parent)

\section{Create a life plan and a training manual}

Each person with $\mathrm{HCN}$ is unique and can function well if his or her unique needs are met in a certain way. Those certain ways of doing things become second nature for parents by the time the child becomes an adult; and hence, the parents are the true experts on the support needs of their adult children with HCN.

It, therefore, becomes crucial that the parents share their expertise with others as part of their succession planning. Whilst we touched upon the need for the parents to educate the people in their informal network, a number of parents felt that it would be important for even the support staff from the formal system to have access to their knowledge of their children's needs. Many parents talked about creating a life plan for their children detailing their support needs, likes and dislikes, and goals and aspirations. This would ensure that, irrespective of the changes in who provides the support, their children's needs and preferences would be known to all even when parents were not around to advocate for them. A couple of parents of children with complex medical conditions suggested that, along with the life plan, they would also need to create an instruction/training manual providing minute details of their children's health and personal care needs and how to meet them. Such a manual could also include pictures and/or videos of parents doing the care themselves so that others would know what exactly needs to be done and how; the details around their children's preferred method of communication and what different signs and gestures mean; their memorandum of wishes; a note on their values; and a list of "dos and don'ts" important for ensuring the safety of their children.

Yeah, it would be like me leaving a manual of me behind [laughs]. So that the next person whoever I would like to take over the guardianship would know my core values. (Louise, Auckland parent)

One Auckland parent had already prepared such a manual and presented a brief description of the manual in the following words:

There is a fifty-page training manual which spells out how to assist me with my health, how to assist me with my mobility, how to take me out to cafe, it also has a whole lot of background knowledge such as who is who in her family, because being non-verbal often you have to initiate the conversation. Lot of photo books and albums, so people can look through that and say "ohhh, this is so and so" - that sort of thing. (Rosemary, Auckland parent)

\section{Prepare the community}

A number of parents from both groups commented that, when it came to their attitude towards disability and disabled people, by and large, the society offered a mixed bag - it had both kinds of people those who accept it and those who do not. They felt that whilst, in general, the society had become more accepting of disabled people, especially over the last couple of decades, due to increased awareness amongst the general public and the emphasis on mainstream education; there was still a lot of ignorance and lack of awareness leading to a lack of societal acceptance of disabled people.

I think people in general just accept but with a "but". I don't think that people really go out of their way to include and they are still - even though attitudes are changing, they still see us as different them and us. (Donna, Auckland parent) 
Not much [acceptance]. This country is not good for disabled people. It doesn't care about - it doesn't think of the disabled people at all. Because we are so many people. There is no regard for a human life in this country. So where is the place for them? (Manju, Delhi parent)

In the experience of both groups of parents, the attitude of the public towards their children included prejudice or disapproval (expressed through strange stares or avoidance); pity or sympathy; patronising or disrespectful attitudes; or in some extreme cases, the use of insulting or abusive language.

A majority of the Delhi parent participants belonged to the Hindu community. They mentioned that, even today, many people of their community believed that being born with a disability or having a child with a disability was a punishment for one's sinful karmas [deeds] of the past life. Due to such beliefs, their attitude in general was not very helpful.

Their thought is that this is some upari hawa [evil power] or this is a fault of the ancestors. They don't believe that this is a medical problem, they just think that this is a result of the sins of the ancestors and these kids are getting punished for that; or they are paying for the sins of their own deed in the previous birth; or you must have done something wrong as a result your kids are like this and so on. (Radhika, Delhi parent)

In relation to changing the attitudes of the community, many parents felt that they themselves needed to be more proactive in preparing the community to accept their children.

I think we as disabled families can do just as much for the public as expecting it back, yeah. Because we have the benefit of knowing our people. They don't know our people, they don't know how to react. (Louise, Auckland parent)
I have noted that this depends on you. If your behaviour towards Jitesh is wrong, the people are also going to look at him in similar manner. If you are looking at Jitesh in a nice manner and showing your affection towards him even in front of the public, then people's attitude also changes accordingly. (Hema, Delhi parent)

According to some parents, one of the best ways of educating the community about their children was taking them out wherever they went and approaching members of the public with a positive attitude rather than a feeling of shame or embarrassment. In many parents' experience, the public generally reciprocated the feelings and hence a positive attitude was more likely to be reciprocated by positivity and acceptance in return.

We go to pools and [the] more times we are out there, [the] more people we are educating. And maybe softening a few hearts out there too. (Wendy, Auckland parent)

Many parents, however, felt that, to bring about a change in community attitudes, it was important that the families checked their own attitude first and changed it, if required. Their suggestions for other parents included accepting their children, believing in their abilities, and loving them for who they are.

Finally, a couple of Auckland parents suggested adopting a cautious approach as, in their views, people could not be forced to accept disability:

You can't force communities to be accepting of people with disabilities for example. It's a human nature thing, it's a choice and it's about making a right choice or being raised in an environment where disability and difference is accepted. It's an evolution - we are still undergoing that evolution. (Lesley, Auckland parent)

To conclude this section on findings, it needs to be mentioned that the parent 
participants of the study were aware that doing succession planning is not an easy task and some parents might find it more difficult than others. Recognising this difficulty, one of the messages that the parent participants had for other parents in similar situations to theirs was around looking after themselves and seeking professional help, where needed.

Don't make a martyr out of yourself. If you need a hand, stick your hand up and say I need a hand, because you are not going to do anybody any favours. (Wendy, Auckland parent)

\section{Discussion and conclusion}

This article has discussed the parents' suggestions on some of the actions that they could take themselves to fulfil their wishes and address some of their worries. Whilst some parents had not given much thought to succession planning, a majority of the parents were aware of the mammoth challenge that lay ahead of them relative to preparing for their children's long-term future beyond their own lifespan.

Whilst the themes identified in the findings section represent the views of both groups of parents and largely have common threads, there are a couple of significant differences worth noting. In relation to the potential future role of the non-disabled siblings in their disabled children's lives, most Indian parents expected them to be their potential successors. On the other hand, most of the New Zealand parents were of the view that their non-disabled children should be able to live their own lives and it was not fair to expect them to have to look after their disabled siblings. Similarly, in relation to securing their disabled children's financial future, whilst most Indian parents expressed a wish to leave as much funds as possible in their disabled children's name; a majority of the New Zealand parents (including those who were financially affluent) expected the state to take full responsibility for their children's future financial needs. A detailed discussion surrounding the reasons for these differences is presented in Thakkar (2017) but is beyond the scope of this article.

With regard to the parents' suggestion around preparing the child to live without them, the literature suggests that, for that to happen, firstly the parents would need to believe in their children. Unfortunately, many parents underestimate their children's abilities and, as a result, have very low expectations of them. It has been suggested that this could often be the result of internalisation on the parents' part of the negative attitudes of the community towards their children and, in turn, could reinforce their dependence and social marginalisation (The World Bank, 2009). Therefore, it is vital that the parents approach this task with a positive attitude and invest time and effort in recognising their children's skills and abilities. At the same time, it is also important that they be realistic about their expectations and do not have false hopes around the level of independence that their children could practically achieve.

The literature also supports the study's findings around creating a circle of support around a disabled child. For example, Taggart et al. (2012) suggested that the concept of circle of support or a "circle of friends" comprising family, friends and the members of the community could be particularly helpful for the social well-being of people with an intellectual disability or high support needs. Further, the literature also suggests that, where such supports are not naturally available to parents, they might need to be facilitated through professional help (Duggan \& Linehan, 2013; McCallin, Dickinson, Weston, AUT University, \& Waitemata District Health Board, 2007; O'Brien, Thesing, \& Capie, 2005). As Morgan (2009) warned, "loneliness is the only real disability" (p. 27) and hence it becomes vital that the parents take appropriate measures to help their children develop long-lasting social networks, friendships and relationships. 
Finally, the literature also supports the study participants" message around "sticking up a hand when needed" and suggests that the parents do not need to do it all alone and the professionals and/or government must provide the parents with appropriate help in succession planning (McCallin et al., 2007; Taggart et al., 2012).

This need for supporting parents with succession planning has specific practice implications, particularly for people working in the social services sector. Professionals, including social workers, who work closely with ageing parents of disabled people in any capacity, have a joint responsibility, not only to raise awareness of timely succession planning, but to support them every step of the way to put things in place. The parents may need support in a number of areas including legal advice around guardianship; creating a circle of support; help connecting with local community; creating a long-term support plan for their children and so on. Thus, a targeted and coordinated approach between professional bodies and government to support these families becomes vital.

As reported by Taggart et al. (2012), there are a number of successful educational programmes such as "Future is Now" in the UK and "Safe and Secure" in Canada designed specifically to assist ageing parents and their supporters with succession planning. Whilst there are some nongovernment organisations in both India and Aotearoa New Zealand that provide support to the parents of disabled children in this area, the governments of both the countries could follow in the UK and Canada's footsteps and develop programmes relevant to their local context with a specific focus on assisting the parents of adult children with $\mathrm{HCN}$ with succession planning.

One of the key limitations of this study is that it focuses only on the views of the parents of adults with HCN and does not include the other close family members such as siblings who can potentially play a major role in supporting their disabled brother or sister once the parents are no longer alive. Therefore, a future study with a specific focus on the views of the siblings caring for adults with HCN would certainly complement the findings of this study and provide further insight into how these families could be better supported.

\section{Acknowledgements}

I would like to thank the participants of my study for generously sharing their views and life experiences, without which this article would not have been possible.

\section{References}

Bennett, C. E. (2002). An emotional roller-coaster: Stories from mothers of young disabled children. New Zealand: Massey University.

Bray, A., Moss, J., Forrester, K., \& McConnochie, K. (2005). Evaluation of the complex carers group project. Dunedin, NZ: Donald Beasley Institute.

Broadbent, D. L. P. (2003). Planning for the future of individuals with developmental disabilities (M.S.). Available from ProQuest Dissertations \& Theses Global. (305298889). Retrieved from http://search.proquest.com.ezproxy. auckland.ac.nz/docview/305298889? accountid=8424

Duggan, C., \& Linehan, C. (2013). The role of "natural supports" in promoting independent living for people with disabilities: A review of existing literature. British Journal of Learning Disabilities, 41(3), 199-207. doi:10.1111/bld.12040

Harrison, J., Henderson, M., \& Leonard, R. (Eds.). (2007). Different dads: Fathers' stories of parenting disabled children. London, UK: Jessica Kingsley.

Hatton, C., Akram, Y., Shah, R., Robertson, J., \& Emerson, E. (2004). Supporting South Asian families with a child with severe disabilities. London, UK: Jessica Kingsley.

Hewitt-Taylor, J. (2008). Children with complex and continuing heath needs: The experiences of children, families and care staff. London, UK: Jessica Kingsley.

James, N. (2013). The formal support experiences of family carers of people with an intellectual disability who also display challenging behaviour and/or mental health issues. Journal of Intellectual Disabilities, 17(1), 6-23. doi:10.1177/1744629512472610

Larkin, M., \& Mitchell, W. (2016). Carers, choice and personalisation: What do we know? Social Policy and Society, 15(2), 189-205. doi:10.1017/S1474746415000299

McCallin, A., Dickinson, A. R., Weston, K., AUT University, \& Waitemata District Health Board. (2007). Family support for children with complex disabilities: Time for action. Auckland, NZ: Waitemata District Health Board.

Milner, P., \& Mirfin-Veitch, B. (2012). I am here: The article 19 project. Dunedin, NZ: Donald Beasley Institute.

Ministry of Health. (2016). New model for supporting disabled people. Retrieved from https://www.health.govt.nz/ourwork/disability-services/disability-projects/new-modelsupporting-disabled-people 
Morgan, P. L. (2009). Parenting an adult with disabilities or special needs: Everything you need to know to plan for and protect your child's future. New York, NY: AMACOM.

O'Brien, P., Thesing, A., \& Capie, A. (2005). Supporting people out of one institution while avoiding another. In P. O'Brien, \& M. Sullivan (Eds.), Allies in emancipation: Shifting from providing service to being of support (pp. 135-150). South Melbourne, VIC: Thomson Dunmore Press.

Pinto, P., \& Sahur, N. (2001). Working with people with disabilities: An Indian perspective. Retrieved from http://cirrie.buffalo.edu/culture/monographs/india/\#sii3

Read, J. (2000). Disability, the family, and society: Listening to mothers. Philadelphia, PA: Open University Press.

Redmond, B., \& Richardson, V. (2003). Just getting on with it: Exploring the service needs of mothers who care for young children with severe/profound and lifethreatening intellectual disability. Journal of Applied Research in Intellectual Disabilities, 16(3), 205-218. doi:10.1046/j.1468-3148.2003.00165.x

Rehabilitation Council of India. (2014). Status of disability in India - 2012. New Delhi, India: Author.

Shaw, K., Cartwright, C., \& Craig, J. (2011). The housing and support needs of people with an intellectual disability into older age. Journal of Intellectual Disability Research, 55(9), 895-903. doi:10.1111/j.1365-2788.2011.01449.x

Taggart, L., Truesdale-Kennedy, M., Ryan, A., \& McConkey, R. (2012). Examining the support needs of ageing family carers in developing future plans for a relative with an intellectual disability. Journal of Intellectual Disabilities, 16(3), 217-234. doi:10.1177/1744629512456465

Thakkar, H. (2017). When I am no longer alive: Understanding parents' views on the future of their disabled adult children with high and complex needs (Doctoral dissertation). Retrieved from https://researchspace.auckland.ac.nz/ handle/2292/36648?show=full

The World Bank. (2009). People with disabilities in India: From commitments to outcomes. Washington, DC: The World Bank.

Vorhaus, J. S. (2014). Philosophy and profound disability: Learning from experience. Disability \& Society, 29(4), 611-623.

Wills, R. (1994). It is time to stop. In K. Ballard (Ed.), Disability, family, whanau and society (pp. 247-264). Palmerston North, NZ: Dunmore Press.

Wong, S., \& Wong, T. (2003). An exploratory study on needs of parents of adults with a severe learning disability in a residential setting. Mental Health Nursing, 24(8), 795-811. 